Gorter, K.J., Tuytel, G.H., Leeuw, J.R.J. de, Bijl, J.J. van der, Bensing, J.M., Rutten, G.E.H.M. Preferences and opinions of patients with type 2 diabetes on education and self-care: a crosssectional survey. Diabetic Medicine: 2010, 27(1), 85-91

\begin{tabular}{|l|l|}
\hline $\begin{array}{l}\text { Postprint } \\
\text { Version }\end{array}$ & 1.0 \\
\hline Journal website & http://www3.interscience.wiley.com/cgi-bin/fulltext/122684260/HTMLSTART \\
\hline Pubmed link & http://www.ncbi.nlm.nih.gov/pubmed/20121894 \\
\hline DOI & $10.1111 / \mathrm{j} .1464-5491.2009 .02886 . \mathrm{x}$ \\
\hline
\end{tabular}

This is a NIVEL certified Post Print, more info at http://www.nivel.eu

\title{
Preferences and opinions of patients with Type 2 diabetes on education and self-care: a cross- sectional survey
}

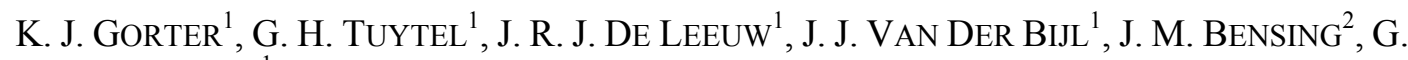 \\ E. H. M. RUTTEN ${ }^{1}$ \\ ${ }^{1}$ Julius Center for Health Sciences and Primary Care, University Medical Center \\ ${ }^{2}$ Nivel Institute, Utrecht, the Netherlands
}

\begin{abstract}
Objective To assess the preferences of patients with Type 2 diabetes regarding self-care activities and diabetes education.

Research design and methods Questionnaire survey carried out in general practices and outpatient clinics across the Netherlands. Outcomes: preferred setting for education, preferred educator, and preferred and most burdensome self-care activity. Multinomial logistic regression analysis assessed associations between outcomes and patient characteristics, preferences and opinions.

Results Data of 994 consecutive individuals were analysed (mean 65 years; 54\% male; $97 \%$ Caucasian; $21 \%$ low education level; $80 \%$ primary care). Of these, $19 \%$ thought they had poor to average glycaemic control, $61 \%$ thought they were over-weight and 32\% thought they took too little exercise. Eighty per cent of respondents preferred diabetes education during regular diabetes checkups. Patients taking insulin preferred education to be given by nurses [odds ratio (OR) 2.45; 95\% confidence interval (CI) 1.21-4.96]. Individuals who thought their health to be poor/average preferred education to be given by doctors (OR 1.65; 95\% CI 1.08-2.53). Physical exercise was the preferred self-care activity of those who thought they took too little exercise (OR 1.97; 95\% CI 1.32-2.93) but was preferred less by patients with mobility problems (OR $0.65 ; 95 \%$ CI 0.43-0.97). Patients with eating disinhibition reported keeping to a healthy diet (OR 4.63; 3.00-7.16) and taking medication (OR 1.66; 95\% CI 1.09-2.52) as the most burdensome self-care activities. Age was not an independent determinant of any preference.

Conclusions When providing education for patients with newly diagnosed Type 2 diabetes, healthcare providers should consider making a tailored education plan, irrespective of the patient's age.

Abbreviations
\end{abstract}


Gorter, K.J., Tuytel, G.H., Leeuw, J.R.J. de, Bijl, J.J. van der, Bensing, J.M., Rutten, G.E.H.M. Preferences and opinions of patients with type 2 diabetes on education and self-care: a crosssectional survey. Diabetic Medicine: 2010, 27(1), 85-91

CI confidence interval DHP-1 Diabetes Health Profile EuroQoL-5D European quality of life scale with five dimensions EuroQoL-VAS European quality of life-visual analogue scale GP general practitioner OGLA oral glucoselowering agent OR odds ratio

\section{INTRODUCTION}

The contribution of education to the self-management abilities of people with diabetes is widely recognized $\left.{ }^{1}\right]$. Diabetes education given in groups or individually is equally effective, although group education may be more cost-effective $\left[{ }^{2}\right]$. While various healthcare professionals can give education, nurses are most often employed as diabetes educators $\left.{ }^{1}\right]$. The applicability and success of educational programmes for people with Type 2 diabetes is influenced by the individual's age, gender, ethnicity and level of education, and thus a targeted approach might be warranted $\left[^{3-6}\right]$. Because the characteristics of patients treated in primary or secondary care differ $\left[{ }^{7}\right]$, treatment setting may be an important determinant of the success of such programmes. Self-efficacy is necessary to improve self-management and self-care $\left[{ }^{8}\right]$. While it is recognized that the patient's opinion about his/her role in diabetes management is an essential aspect of diabetes care $[9,10]$, in daily practice patients are not routinely asked about their opinions and preferences. For instance, patients could be asked about their preferred setting for education, preferred educator, preferred self-care activity and least preferred self-care activity $\left[^{10}\right]$. Although meta-analyses have been performed regarding diabetes education and advised lifestyle changes, many included randomized clinical trials of interventions by healthcare providers or reviews that did not consider all relevant patient outcome parameters $\left[{ }^{11,12}\right]$. As a consequence, little is known about peoples' preferences about their diabetes education and advised lifestyle changes.

This survey aims to study the association between peoples' preferred setting of education, preferred educator, preferred self-care activity and least preferred self-care activity, on the one hand, and their characteristics, preferences and opinions on the other.

\section{PATIENTS AND METHODS}

\section{Settings}

In 2007, general practitioners (GPs) $(n=80)$ and endocrinologists $(n=13)$ across the Netherlands participated in this study. Over a 3-month period, consecutive patients with Type 2 diabetes were recruited by their own care providers during regular check-ups at the practice or outpatient clinic. Patients were asked to complete a questionnaire about their preferences and opinions about diabetes education and self-care activities in the waiting room and to return it anonymously in a prepaid envelope. It was stressed that it was of utmost importance that their opinion should be heard on these topics.

\section{Measures}

Based on qualitative research $\left[{ }^{10}\right]$, we assessed four different multinomial outcomes. (i) Preferred setting of education: during regular diabetes check-ups, during a special course or no preference; (ii) preferred educator: my GP/endocrinologist, my diabetes/practice nurse or no preference; (iii) preferred self-care activity: pay more attention to what I eat, be more physically active or no preference; (iv) most burdensome self-care activity: pay attention to what I eat, be more physically active, taking my medication or no preference. We also assessed possible determinants of the above-mentioned preferences such as age, gender, educational level, ethnicity, setting of diabetes treatment $\left[{ }^{13}\right]$, duration of diabetes, diabetes medication, the presence of macro- or microvascular complications and quality of life. The latter consisted of mobility problems, self-care problems, pain, and anxiety/depression measured by European quality of life scale with five dimensions (EuroQol-5D), general well-being measured using the EuroQol-visual analogue scale (EuroQoL-VAS) (score range 
Gorter, K.J., Tuytel, G.H., Leeuw, J.R.J. de, Bijl, J.J. van der, Bensing, J.M., Rutten, G.E.H.M. Preferences and opinions of patients with type 2 diabetes on education and self-care: a crosssectional survey. Diabetic Medicine: 2010, 27(1), 85-91

$0-100$, where 100 represents best imaginable health status) $\left[{ }^{14}\right]$ and three subscales from the Diabetes Health Profile (DHP-1), namely barriers to activity, psychological distress and disinhibited eating $\left[{ }^{15}\right]$. Disinhibited eating, or eating disinhibition, refers to the temporary loss of control of eating behaviour because of emotional arousal, examples of which are eating when not hungry, overeating and binge eating $\left[{ }^{16}\right]$. Lastly, we measured participants' opinions on perceived glycaemic control, weight and physical exercise, using 5-point Likert scales (range from very poor to very good). The questionnaire was pretested and piloted in 10 people with Type 2 diabetes and its face validity was assessed by two physicians, a psychologist and a nurse.

\section{Statistical analysis}

Data were analysed using spss for Windows (version 12.0.1, SPSS Inc., Chicago, IL, USA). Self-reported categorical outcomes were analysed as percentages. We compared the multinomial outcomes with 'no preference' as a reference category and using the backward stepwise method we identified which determinants were independently associated with the categorical outcome variables. These were expressed in odds ratios (ORs) and their corresponding $95 \%$ confidence interval (CI). Possible determinants were analysed as proportions. For use in daily practice, all determinants, except diabetes medication [none; oral glucose-lowering agents (OGLAs); insulin with or without OGLA use], were dichotomized including age ( $\leq 64$ years; $\geq 65$ years), ethnicity (Caucasian yes/no), educational level [completed only primary school or less (low) vs. others (high)], setting of diabetes treatment (primary vs. secondary care), duration of diabetes ( $<5$ years; $\geq 5$ years), presence of macro- or microvascular complications (yes/no) and also participants' perceived glycaemic control [average/(very) poor vs. (very) good], weight [(much) too low/good vs. (much) too high], physical exercise [(just) enough/(more than) enough vs. (much) too little], mobility problems (none vs. some/serious), self-care problems (none vs. some/serious), pain/discomfort (none vs. some/serious) and anxiety/depression (none vs. some/serious). For comparison with EuroQol-VAS scores, DHP-1 scores were recoded (score range of 0-100, where 100 represents no dysfunction). We dichotomized according to the median for the results of the EuroQol-VAS (poor vs. good) and the three subscales of the DHP-1: barriers to activity (yes/no), psychological distress (yes/no) and eating disinhibition (yes/no). Interquartile ranges (25-75\%) are given to provide extra information. We tested for collinearity by analysing each determinant as an outcome in a regression model; all other determinants were used as independent variables. The setting of diabetes treatment (primary vs. secondary care) was entered in the model as a separate determinant of the outcomes. All possible determinants of the outcomes were entered backward stepwise in a multinomial logistic regression analysis $(\mathrm{P}<0.05)$. We repeated the complete procedure with age as a continuous variable.

\section{RESULTS}

Of 1029 consecutive patients with Type 2 diabetes who participated, the data for 994 could be analysed. Of these, $792(80 \%)$ were mainly treated in primary care, the remainder being treated in secondary care. The number of questionnaires returned per practice varied between six and 13 . We have no data about the non-responders. The included patients had a mean age of $65 \pm 10.3$ years (mean $\pm \mathrm{sd}$ ), $54 \%$ were male, $97 \%$ were of Western ethnicity and $21 \%$ had completed only primary school or less $\left({ }^{\text {Table }}{ }^{1}\right)$. Compared with patients with Type 2 diabetes treated in secondary care, those treated in primary care were older, had a shorter duration of diabetes, used insulin less frequently and had fewer complications. 
Gorter, K.J., Tuytel, G.H., Leeuw, J.R.J. de, Bijl, J.J. van der, Bensing, J.M., Rutten, G.E.H.M. Preferences and opinions of patients with type 2 diabetes on education and self-care: a crosssectional survey. Diabetic Medicine: 2010, 27(1), 85-91

\section{[TABLE1]}

\section{Preferences}

Of all respondents, $83 \%$ preferred to receive education during their regular diabetes checkups $\left({ }^{\text {Table } 2}\right), 37 \%$ preferred education by a nurse and 3\% preferred a special diabetes course. The preferred self-care activity was physical activity (reported by $37 \%$ of all participants) and this preference was more pronounced among participants treated in secondary care. The most burdensome self-care activity was taking diabetes medication (reported by $26 \%$ of all participants) and this was especially the case among participants treated in primary care.

\section{[TABLE 2]}

\section{Determinants of patients' preferences}

We did not enter ethnicity as a determinant in the multinomial analysis as fewer than $3 \%$ of participants were of non-Western ethnicity. We did not find collinearity.

\section{Preferred setting of education: during regular check-up or during a special course}

As only 3\% of the participants preferred a special diabetes course, we did not perform further analyses because of skewness of the distribution of the outcomes.

\section{Preferred person to give education: a doctor or a nurse}

Among the patients who expressed a preference compared with the patients without a preference, none of the possible determinants independently influenced patient preference, except that patients using insulin with or without OGLAs preferred education by nurses (OR $2.45 ; 95 \%$ CI 1.21-4.96), while patients who perceived their health status as poor to average preferred education by a doctor (OR 1.65; 95\% CI 1.08-2.53) (no table).

\section{Preferred self-care activity: more physical exercise or keeping a healthy diet}

Among the patients who expressed a preference compared with the patients without a preference, gender, primary care provider, perceived weight, perceived physical exercise, mobility problems and eating disinhibition all independently influenced patient preference, but age and educational level did not. Patients who felt they took too little exercise preferred taking more physical exercise (OR 1.97; 95\% CI 1.32-2.93) and patients who thought they were too heavy preferred keeping to a healthy diet (OR 1.64; 95\% CI 1.05-2.57). Patients with eating disinhibition preferred both taking more physical exercise (OR 1.62; 95\% CI $1.13-2.34$ ) and keeping to a healthy diet (OR 1.72; 95\% CI 1.15-2.58). Men preferred taking more physical exercise (OR $1.46 ; 95 \%$ CI $1.02-2.10$ ). Patients who were treated in primary care (OR $0.49 ; 95 \%$ CI $0.31-0.76$ ) or who had mobility problems (OR 0.65 ; $95 \%$ CI $0.43-$ 0.97 ) considered preferred physical exercise less $\left({ }^{\text {Table } 3}\right)$.

\section{[TABLE 3]}

Most burdensome self-care activity: physical exercise, keeping to a healthy diet or taking medication

Among the patients who expressed a specific preference compared with the patients without a preference, educational level, duration of diabetes, perceived physical exercise and eating disinhibition independently influenced patient preference, but age, gender and treatment in primary care did not. Physical exercise was considered the most burdensome self-care activity among patients who thought they took too little exercise (OR 5.03; 95\% CI 2.88-8.79), whereas people with eating disinhibition found keeping to a healthy diet (OR 4.63 ; 95\% CI 3.00-7.16) and taking medications (OR 1.66; 95\% CI 1.09-2.52) to be the most burdensome self-care activities. Taking medication was not considered particularly 
Gorter, K.J., Tuytel, G.H., Leeuw, J.R.J. de, Bijl, J.J. van der, Bensing, J.M., Rutten, G.E.H.M. Preferences and opinions of patients with type 2 diabetes on education and self-care: a crosssectional survey. Diabetic Medicine: 2010, 27(1), 85-91

burdensome by people with a low educational level (OR 0.59; 95\% CI 0.35-0.99) or longer duration of diabetes (OR 0.59; 95\% CI 0.39-0.89) ${ }^{\text {Table } 4}{ }^{4}$ ).

\section{[TABLE 4]}

\section{Discussion}

More than $80 \%$ of the participants with Type 2 diabetes preferred to receive diabetes education during their regular diabetes check-ups. Of the participants who expressed a preference for a doctor or a nurse as educator, those who used insulin preferred nurses and those who considered their health to be poor-average preferred doctors. A preference for specific self-care activities was expressed by males, by people with perceived physical inactivity, by people who felt they were too heavy and by people with eating disinhibition. Physical activity was preferred less by people in primary care and by people with mobility problems. Taking physical exercise was considered most burdensome by people with physical inactivity and taking medication or keeping to a healthy diet were considered most burdensome by people with eating disinhibition. Taking medication was not considered particularly burdensome by people with a low educational level and longer duration of diabetes. Age was not a determinant of any preference.

\section{COMPARISON WITH THE EXISTING LITERATURE}

\section{Preferred setting}

We found that most people with Type 2 diabetes preferred not to receive diabetes education by means of a special diabetes course. This is consistent with the opinion of Dutch experts that diabetes education should be integrated into daily diabetes care $\left[{ }^{17}\right]$. Nowadays, most Dutch general practices provide multidisciplinary care for diabetic patients, involving both GPs and practice nurses for diabetes.

\section{Preferred educator}

Six out of ten participants preferred either a nurse or a doctor to give them diabetes education. Although various healthcare professionals can give diabetes education, nurses are usually employed for this $\left[{ }^{1}\right]$. As most patients with Type 2 diabetes who use insulin have their insulin use monitored by nurses, it is not surprising that this group prefers nurses as educators $\left[{ }^{18}\right]$. Participants who felt that their health was poor to average preferred to be given education by a doctor. As in the Netherlands only doctors are allowed to prescribe medication, this preference may reflect the presumption that doctors rather than nurses may be in the position to improve the patients' physical health. However, a study has shown that the most robust improvements in glycaemic control were achieved when medication adjustments were made without doctor approval $\left[{ }^{19}\right]$. This should be borne in mind in future studies to improve diabetes care. Reviews comparing the effectiveness of different disciplines in providing education report mixed results $\left[{ }^{1}\right]$. While doctors establish the diagnosis of diabetes and start prescribing diet and medication, this is only the beginning of an educational process for the patient $\left[{ }^{18}\right]$. Indeed, a multidisciplinary approach that includes patient-defined goals and outcomes facilitating patients' inner motivation, and a personalized follow-up plan may be essential to successful diabetes management $\left[{ }^{20}\right]$. Thus, patient education should be individualized on the basis of the patient's health beliefs and attitudes $\left[{ }^{8,20}\right]$.

\section{Preferred self-care}

More physical exercise was a preferred self-care activity among men in particular. An earlier survey on self-care activities conducted among people with diabetes showed that women visited their dietician more often, whereas men exercised much more $\left[{ }^{21}\right]$. Our 
Gorter, K.J., Tuytel, G.H., Leeuw, J.R.J. de, Bijl, J.J. van der, Bensing, J.M., Rutten, G.E.H.M. Preferences and opinions of patients with type 2 diabetes on education and self-care: a crosssectional survey. Diabetic Medicine: 2010, 27(1), 85-91

findings stress the importance of taking men's and women's preferences into account when tailoring diabetes education.

Participants who considered themselves overweight indicated that keeping to a healthy diet was their preferred self-care activity. Healthcare providers should take patients' perceived weight into account when they discuss lifestyle advice, especially because dietary selfmanagement is often seen as a burden $\left[{ }^{22}\right]$. Participants who thought they took too little physical activity mentioned more physical exercise as both their preferred but also most burdensome self-care activity. We hypothesize that, although these people know that more exercise would be good for them, they do not like doing it (and hence refer to it as burdensome). In these circumstances, education in a prescriptive framework or with motivational interviewing may not suffice to achieve and maintain behavioural change and, instead, self-management by pro-active coping may be required $\left[{ }^{23}\right]$.

Participants with eating disinhibition expressed a preference for more physical exercise as self-care activity. These individuals also mentioned keeping to a healthy diet as both their preferred and most burdensome self-care activity. This probably reflects their ambivalence about healthy eating and may have an impact on the translation of beliefs and attitudes into behaviour $\left.{ }^{24}\right]$.

Guidelines for diabetes self-management education emphasize that the importance of considering demographic variables such as age in order to maximize its effectiveness in specific populations $\left.{ }^{25}\right]$. Indeed, a study investigating whether age affected self-management of diabetes found that older people had less difficulty adhering to dietary requirements than younger people $\left[{ }^{26}\right]$. However, we did not find age to be an independent determinant of any of the preferences and opinions.

\section{STRENGTHS AND LIMITATIONS}

This is a robust study of patient preferences and opinions about diabetes education involving patients treated in primary and secondary care in the Netherlands. The study has some limitations. Firstly, we recruited consecutive patients and could not control for possible selection bias. However, the participants were recruited from both primary and secondary care services and their mean age, gender and educational level were representative of the Dutch population of people with Type 2 diabetes $\left.{ }^{7,27}\right]$. However, findings cannot be generalized to persons with non-Western ethnicity. Secondly, this study did not take into account clustering within practices or outpatient clinics, but, as 13 or fewer questionnaires were returned per practice or clinic, the effect of clustering may be not relevant. Thirdly, we did not assess health literacy and thus cannot comment on whether patients with impaired health literacy, such as elderly people, may require a special educational format $\left.{ }^{5}\right]$. This is important because a low uptake of education may reflect patients' desire to continue in a passive role, so called 'learned helplessness' $\left[{ }^{28}\right]$.

\section{CONCLUSION}

Education should be part of regular diabetes check-ups. Diabetes care providers may consider asking patients about their preferences during the consultation and make a tailored education plan to reflect the patient's preference regarding group or individual education and which self-care activity should be implemented first (stopping smoking, adjusting dietary habits or improving physical activity). Lastly, healthcare providers should be aware that there may be specific barriers to lifestyle advice. These aspects should be taken into consideration when updating Type 2 diabetes guidelines.

\section{COMPETING INTERESTS}

Nothing to declare. 
Gorter, K.J., Tuytel, G.H., Leeuw, J.R.J. de, Bijl, J.J. van der, Bensing, J.M., Rutten, G.E.H.M. Preferences and opinions of patients with type 2 diabetes on education and self-care: a crosssectional survey. Diabetic Medicine: 2010, 27(1), 85-91

\section{Acknowledgements}

We thank patients who participated in this study and their primary care providers.

Furthermore we acknowledge Ms Rebecca Stellato and Mr Peter Zuithoff for their statistical support. This study was made possible through a grant of the Dutch Diabetes Foundation (grant 2005.13.021).

\section{REFERENCES}

1 Gary TL, Genkinger GM, Guallar F, Peyrot M, Brancati FL. Meta-analysis of randomized educational and behavioral interventions in type 2 diabetes. Diabetes Educ 2003; 29: 488501.

2 Rickheim PL, Weaver TW, Flader JL, Kendall DM. Assessment of group versus individual diabetes education. Diabetes Care 2002; 25: 269-274.

3 Sarkar U, Fisher L, Schillinger D. Is self-efficacy associated with diabetes selfmanagement across race/ethnicity and health literacy? Diabetes Care 2006; 29: 823-829.

4 Brown AF, Gregg EW, Stevens MR, Karter AJ, Weinberger M, Safford MM et al. Race, ethnicity, socioeconomic position and quality of care for adults with diabetes enrolled in managed care. Diabetes Care 2005; 28: 2864-2870.

5 Schillinger D, Grumbach K, Piette J, Wang F, Osmond D, Daher C et al. Association of health literacy with diabetes outcomes. J Am Med Assoc 2002; 288: 475-482.

6 Thoolen BJ, Ridder de DT, Bensing JM, Gorter KJ, Rutten GEHM. Who participates in diabetes self-management interventions? Issues of recruitment and retainment. Diabetes Educ 2007; 33: 465-474.

7 Bruggen van JAR, Gorter KJ, Stolk RP, Rutten GEHM. Overall quality of diabetes care in a defined geographic region: different sides of the same story. Br J Gen Pract 2008; 58: 339345.

8 Aljasem LI, Peyrot M, Wissow L, Rubin RR. The impact of barriers and self-efficacy on self-care behaviors in type 2 diabetes. Diabetes Educ 2001; 27: 393-404.

9 Lawton J, Parry O, Peel E, Douglas M. Diabetes service provision: a qualitative study of newly diagnosed Type 2 diabetes patients' experiences and views. Diabet Med 2005; 22: 1246-1251.

Direct Link:

10 Vég A, Rosenqvist U, Sarkadi A. Variation of patients' views on Type 2 diabetes management over time. Diabet Med 2007; 24: 408-414.

Direct Link:

11 Lenz M, Steckelberg A, Richter B, Mühlhauser I. Meta-analysis does not allow appraisal of complex interventions in diabetes and hypertension self-management: a methodological review. Diabetologia 2007; 50: 1375-1383.

12 Wens J, Vermeire E, Hearnshaw H, Lindenmeyer A, Biot Y, Van Royen P. Educational interventions aiming at improving adherence to treatment recommendations in type 2 diabetes A sub-analyses of a systematic review of randomised controlled trials. Diabetes Res Clin Pract 2008; 79: 377-388.

13 American Diabetes Association: Clinical practice recommendations 2005. Diabetes Care 2005; 28: S1-S79.

14 Brooks R. EuroQol: the current state of play. Health Policy 1996; 37: 53-72.

15 Goddijn P, Bilo H, Meadows K, Groenier K, Feskens E, Meyboom-de Jong B. The validity and reliability of the Diabetes Health Profile (DHP) in NIDDM patients referred for insulin therapy. Qual Life Res 1996; 5: 433-442.

16 Keller K. Encyclopedia of Obesity. London: SAGE Publications, 2008.

17 Van Den Arend IJ, Rutten GE, Schrijvers GJ, Stolk RP. Experts' opinions on the profile of optimal care for patients with diabetes mellitus type 2 in the Netherlands. Neth J Med 2001; 6: 225-231.

18 Myers SA. Diabetes management by the patient and a nurse practitioner. Nurs Clin North Am 1977; 12: 415-426.

19 Shojania KG, Ranji SR, McDonald KM, Grimshaw JM, Sundaram V, Rushakoff RJ et al. Effects of quality improvement strategies for type 2 diabetes on glycemic control: a metaregression analysis. J Am Med Assoc 2006; 296: 427-440. 
Gorter, K.J., Tuytel, G.H., Leeuw, J.R.J. de, Bijl, J.J. van der, Bensing, J.M., Rutten, G.E.H.M. Preferences and opinions of patients with type 2 diabetes on education and self-care: a crosssectional survey. Diabetic Medicine: 2010, 27(1), 85-91

20 Funnell MM, Anderson RM. AADE position statement: individualization of diabetes selfmanagement education. Diabetes Educ 2007; 33: 45-49.

21 Vija S, Stuart NS, Fitzgerald JT, Ronis DL, Hayward RA, Slater S et al. Barriers to following dietary recommendations in type 2 diabetes. Diabet Med 2005; 22: 32-38.

22 Weijman I, Ros WJ, Rutten GE, Schaufeli WB, Schabracq MJ, Winnubst JA. Frequency and perceived burden of diabetes self-management activities in employees with insulintreated diabetes: relationships with health outcomes. Diabetes Res Clin Pract 2005; 68: $56-64$.

23 Thoolen BJ, Ridder de DT, Bensing JM, Gorter KJ, Rutten GEHM Beyond good intentions: the development and evaluation of a proactive self-management course for patients recently diagnosed with type 2 diabetes. Health Educ Res 2007;

24 Peyrot M, Rubin RR, Lauritzen T, Snoek FJ, Matthews DR, Skovlund SE. Psychosocial problems and barriers to improved diabetes management: results of the cross-national Diabetes Attitudes, Wishes and Needs study. Diabet Med 2005; 22: 1379-1385.

25 Funnell MM, Brown TL, Childs BP, Haas LB, Hosey GM, Jenssen B et al. National standards for diabetes self-management education. Diabetes Care 2007; 30: 1630-1637. 26 Lo R, MacLean D. A survey of people with diabetes in northern New South Wales: problems with self-care. Int J Nurs Pract 1996; 2: 11-20.

27 Westert GP, Schellevis FG, Bakker de DH, Groenewegen PP, Bensing JM, Van der Zee J. Monitoring health inequalities through general practice: the Second Dutch National Survey of General Practice. Eur J Public Health 2005; 15: 59-65.

28 Snoek FJ. Self management of type 2 diabetes. Br Med J 2007; 335: 458-459. 
Gorter, K.J., Tuytel, G.H., Leeuw, J.R.J. de, Bijl, J.J. van der, Bensing, J.M., Rutten, G.E.H.M.

Preferences and opinions of patients with type 2 diabetes on education and self-care: a crosssectional survey. Diabetic Medicine: 2010, 27(1), 85-91

\section{TABLES}

\section{Table 1}

Table 1 Basel ine characteristics and opinions of the total study population ( $\mathrm{n}=994)$, subdivided in setting of Type $2 \mathrm{DM}$ treatment primary (n $=792$ ) and secondary care $(n=202)$

\begin{tabular}{|c|c|c|c|c|c|}
\hline & $n$ & & Total $(\%)$ & $\begin{array}{l}\text { Primary } \\
(\% \text { of } n=792)\end{array}$ & $\begin{array}{l}\text { Secondary } \\
(\% \text { of } n=202)\end{array}$ \\
\hline \multirow[t]{4}{*}{ Age (years) } & & $\operatorname{Mean} \pm \mathrm{sD}$ & $65.1 \pm 10.3$ & $65.7 \pm 10.4$ & $62.8 \pm 9.5$ \\
\hline & 994 & $\leq 64$ & 47.8 & 22.4 & 20.1 \\
\hline & & $65-74$ & 321 & 57.7 & 66.4 \\
\hline & & 275 & 20.1 & 19.9 & 13.5 \\
\hline \multirow[t]{2}{*}{ Gender } & 994 & Male & 53.7 & 53.5 & 54.5 \\
\hline & & Female & 46.3 & 46.5 & 45.5 \\
\hline \multirow[t]{2}{*}{ Ethnixity } & 971 & Western & 97.1 & 97.0 & 97.5 \\
\hline & & Non-Western & 29 & 3.0 & 25 \\
\hline \multirow[t]{3}{*}{ Education level } & 987 & Low & 20.6 & 20.1 & 224 \\
\hline & & Mediam & 64.6 & 66.4 & 57.7 \\
\hline & & High & 14.8 & 13.5 & 19.9 \\
\hline \multirow[t]{3}{*}{ Duration diabers (years) } & 959 & $<5$ & 43.5 & 50.2 & 17.7 \\
\hline & & $5-10$ & 28.2 & 28.0 & 28.8 \\
\hline & & $>10$ & 28.4 & 21.8 & 53.5 \\
\hline \multirow[t]{3}{*}{ Medication diabetes } & 971 & None & 9.8 & 12.2 & .5 \\
\hline & & OGLAs & 59.5 & 71.2 & 14.1 \\
\hline & & Insulin with or without OGLA & 30.7 & 16.7 & 85.4 \\
\hline \multirow[t]{2}{*}{ Complications DM } & 956 & No & 627 & 66.2 & 48.7 \\
\hline & & Yes & 37.3 & 33.8 & 51.3 \\
\hline EuroQol-VAS $(0-100)$ & & Mean $\pm s D$ & $74.0 \pm 15.8$ & $69.8 \pm 17.2$ & $69.8 \pm 17.2$ \\
\hline \multirow[t]{3}{*}{ Perceived health status } & & (jinterquartile nange) & (65-85) & $\{67-85\}$ & $(60-80)$ \\
\hline & 913 & Poor-avenage $(0-75)^{*}$ & 53.5 & 50.9 & 63.4 \\
\hline & & Good $(76-100)^{*}$ & 46.5 & 49.1 & 36.6 \\
\hline \multirow[t]{2}{*}{ Mohility problems } & 991 & None & 623 & 64.9 & 51.7 \\
\hline & & Some/serious & 37.7 & 35.1 & 48.3 \\
\hline \multirow[t]{2}{*}{ Self-care problems } & 991 & Nane & 95.9 & 96.5 & 93.5 \\
\hline & & Same/serious & 4.1 & 3.5 & 6.5 \\
\hline \multirow[t]{2}{*}{ Pain/discomfort } & 986 & Nane & 51.3 & 53.3 & 43.5 \\
\hline & & Same/serious & 48.7 & 46.7 & 56.5 \\
\hline \multirow[t]{2}{*}{ Anxiety/depression } & 989 & None & 79.7 & 80.5 & 76.5 \\
\hline & & Some/serious & 20.3 & 19.5 & 23.5 \\
\hline \multirow[t]{4}{*}{ DHP Barriers to activity $(0-100)$} & & $\operatorname{Mean} \pm \mathrm{sD}$ & $85.9 \pm 13.2$ & $87.7 \pm 11.7$ & $79.4 \pm 16.8$ \\
\hline & & (interquartile nange) & $(80.6-94.4)$ & (83.3-97.2) & $(69.4-91.7)$ \\
\hline & 929 & No $(89-100)^{*}$ & 48.5 & 53.1 & 31.3 \\
\hline & & $\mathrm{Yes}(0-88.9)^{*}$ & 51.5 & 46.9 & 68.7 \\
\hline \multirow[t]{4}{*}{ DHP Eating dis inbition $(0-100)$} & & Mean \pm SD & $70.1 \pm 19.6$ & $70.3 \pm 19.6$ & $69.5 \pm 19.8$ \\
\hline & & (interquartile range) & $(60.0-86.7)$ & $(60.0-86.7)$ & $(60.0-86.7)$ \\
\hline & 968 & No $(66.8-100)^{*}$ & 55.6 & 56.8 & 51.0 \\
\hline & & Yes $(0-66.7)^{*}$ & 44.4 & 43.2 & 49.0 \\
\hline \multirow[t]{4}{*}{ DHP Distress $(0-100)$} & & $\operatorname{Mean} \pm \mathrm{sD}$ & $88.9 \pm 8.1$ & $89.6 \pm 7.4$ & $86.3 \pm 10.0$ \\
\hline & & (interquartile nange) & (85.7-95.2) & (85.7-95.2) & (81.0-92.9) \\
\hline & 905 & No $(90.6-100)^{*}$ & 45.0 & 47.6 & 35.1 \\
\hline & & $Y e s(0-90.5)^{*}$ & 55.0 & 52.4 & 64.9 \\
\hline \multirow[t]{2}{*}{ Opinion glycaemic control } & 962 & (very) Good & 814 & 84.7 & 68.8 \\
\hline & & Aver age/(very) poor & 18.6 & 15.3 & 31.2 \\
\hline \multirow[t]{2}{*}{ Opinion weight } & 987 & (much) Too bow/good & 38.6 & 41.0 & 29.2 \\
\hline & & (much) To high & 614 & 59.0 & 70.8 \\
\hline \multirow[t]{2}{*}{ Opinion physical exercise } & 988 & (much) Too little & 31.5 & 29.6 & 38.6 \\
\hline & & Just enough/(more than) enough & 68.5 & 70.4 & 61.4 \\
\hline
\end{tabular}


Gorter, K.J., Tuytel, G.H., Leeuw, J.R.J. de, Bijl, J.J. van der, Bensing, J.M., Rutten, G.E.H.M. Preferences and opinions of patients with type 2 diabetes on education and self-care: a crosssectional survey. Diabetic Medicine: 2010, 27(1), 85-91

\section{Table 2}

Table 2 Preferences of patiens $(n=994)$; self reported cuxomes of the total study population, subdivided according to the setting of diabetes treatment: primary $(n=792)$ and secondary care $(n=202)$

\begin{tabular}{|c|c|c|c|c|c|}
\hline Topic & $n$ & & Total $(\%)$ & $\begin{array}{l}\text { Primary } \\
(\% \text { of } n=792)\end{array}$ & $\begin{array}{l}\text { Secondary } \\
\text { ( } \% \text { of } n=202 \text { ) }\end{array}$ \\
\hline \multirow[t]{3}{*}{ Prefer red setting of education } & \multirow[t]{3}{*}{938} & During regular DM check-ups & 82.7 & 83.7 & 78.8 \\
\hline & & Special DM course & 3.4 & 27 & 6.5 \\
\hline & & No preference & 13.9 & 13.7 & 14.7 \\
\hline \multirow[t]{3}{*}{ Prefer red pers on to give oducation } & \multirow[t]{3}{*}{923} & GP/specialist & 20.5 & 220 & 14.0 \\
\hline & & Diabetes/practice nurse & 36.8 & 34.1 & 48.0 \\
\hline & & No preference & 42.7 & 43.8 & 38.0 \\
\hline \multirow[t]{3}{*}{ Prefer red self-care activity } & \multirow[t]{3}{*}{974} & More physical exercise & 37.2 & 34.3 & 48.5 \\
\hline & & Keeping a healthy diet & 24.4 & 24.3 & 25.0 \\
\hline & & No preference & 38.4 & 41.4 & 26.5 \\
\hline \multirow[t]{4}{*}{ Most burdenoome self care activity } & \multirow[t]{4}{*}{928} & Physical exercise & 12.9 & 13.0 & 12.7 \\
\hline & & Keeping a healthy diet & 23.1 & 227 & 24.3 \\
\hline & & Taking medication & 26.0 & 26.9 & 22.2 \\
\hline & & No preference & 38.0 & 37.3 & 40.7 \\
\hline
\end{tabular}

DM, diabers mellitus.

Table 3

Table 3 Dexerminants of preferred selficare activity by malinomial logistic analysis expressod as odds ratios (ORs) with 95\% confidence intervals (CIs)

\begin{tabular}{|c|c|c|c|c|}
\hline \multirow[b]{3}{*}{ Outcame } & \multicolumn{4}{|c|}{ Prefer red self-care activity ${ }^{*}(n=725)$} \\
\hline & \multicolumn{2}{|c|}{ More physical exercise } & \multicolumn{2}{|c|}{ Keeping a healthy diet } \\
\hline & $\begin{array}{l}n=278 \\
(38.3 \%)\end{array}$ & $\begin{array}{l}\text { Adjustedt } \\
\text { OR }(95 \% \text { CI) }\end{array}$ & $\begin{array}{l}n=179 \\
(24.7 \%)\end{array}$ & $\begin{array}{l}\text { Adjustedt } \\
\text { OR }(95 \% \text { Cl) }\end{array}$ \\
\hline Age & $278(38.3 \%)$ & $0.99\{0.97-1.01\}$ & $179(24.7 \%)$ & $1.00(0.9 \mathrm{~g}-1.02)$ \\
\hline \multicolumn{5}{|l|}{ Gender } \\
\hline Male & $180(43.1 \%)$ & $1.46(1.02-2.10)$ & $87(20.8 \%)$ & $0.80,0.54-1.19)$ \\
\hline \multicolumn{5}{|l|}{ Education level } \\
\hline Low & $53(39.6 \%)$ & $1.19(0.75-1.88)$ & $32(23.9)$ & $0.87,0.52-1.46)$ \\
\hline \multicolumn{5}{|c|}{ Setting of diabers treatment } \\
\hline Primary care & $202(35.5 \%)$ & $0.49(0.31-0.76)$ & $140(24.6 \%)$ & $0.71,0.43-1.17)$ \\
\hline \multicolumn{5}{|l|}{ Opinion weight } \\
\hline (much) Too high & $168(37.0 \%)$ & $0.83(0.57-1.22)$ & $132(29.1 \%)$ & $1.64(1.05-2.57)$ \\
\hline \multicolumn{5}{|c|}{ Opinion physical exercise } \\
\hline (much) Too little & $107(44.0 \%)$ & $1.97(1.32-2.93)$ & $68(28.0 \%)$ & $1.43 \$ 0.92-2.21\}$ \\
\hline \multicolumn{5}{|l|}{ Mohility problems } \\
\hline Some/sericus & $83(31.9 \%)$ & $0.65(0.43-0.97)$ & $82(31.5 \%)$ & $1.26,0.82-1.94)$ \\
\hline \multicolumn{5}{|l|}{ Eating disinhibition } \\
\hline Yes & $131(40.8 \%)$ & $1.62(1.13-2.34\})$ & $95(29.6 \%)$ & $1.72(1.15-258)$ \\
\hline
\end{tabular}

-The reference category is: no preference.

†Alvo adjusted for perceived health sta tus, self-care problems, pain/discomfort, anviety/depreswion, barriers to activity,

distress and opinion about glycaemic control. 
Gorter, K.J., Tuytel, G.H., Leeuw, J.R.J. de, Bijl, J.J. van der, Bensing, J.M., Rutten, G.E.H.M. Preferences and opinions of patients with type 2 diabetes on education and self-care: a crosssectional survey. Diabetic Medicine: 2010, 27(1), 85-91

\section{Table 4}

Table 4 Dexrminants of most burdenvme self-care activity by multinomial log ivic analysis expressed as odds ratios (ORs) with $95 \%$ confidence imtervals (C:

\begin{tabular}{|c|c|c|c|c|c|c|}
\hline \multirow[b]{3}{*}{ Outcame } & \multicolumn{6}{|c|}{ Most burdensome self-care activity $(n=688$ ) } \\
\hline & \multicolumn{2}{|c|}{ Physical exerdise } & \multicolumn{2}{|c|}{ Keeping a healthy diet } & \multicolumn{2}{|c|}{ Taking medication } \\
\hline & $\begin{array}{l}n=86 \\
(12.3 \%)\end{array}$ & $\begin{array}{l}\text { Adjustedt } \\
\text { OR }(95 \% \text { CI) }\end{array}$ & $\begin{array}{l}n=169 \\
(24.1 \%)\end{array}$ & $\begin{array}{l}\text { Adjusted } \uparrow \\
\text { OR }(95 \% \text { CI) }\end{array}$ & $\begin{array}{l}n=180 \\
(25.7 \%)\end{array}$ & $\begin{array}{l}\text { Adjustedt } \\
\text { OR }(95 \% \text { Cl) }\end{array}$ \\
\hline Age & $86(12.3 \%)$ & $1.00(0.97-1.02)$ & $169\{24.1 \%\}$ & $0.98\{0.96-0.999\}$ & $180(25.7 \%)$ & $0.99(0.97-1.01)$ \\
\hline \multicolumn{7}{|l|}{ Gender } \\
\hline Male & $49(12.4 \%)$ & $1.13(0.66-1.93)$ & $105\{26.5 \%)$ & $1.50\langle 0.98-2.31\}$ & $92(23.2 \%)$ & $0.80(0.54-1.18)$ \\
\hline \multicolumn{7}{|l|}{ Education kevel } \\
\hline Low & $13(10.4 \%)$ & $0.60\langle 0.30-1.21\}$ & $27(21.6 \%)$ & $0.78(0.45=1.35)$ & $26(20.8 \%)$ & $0.59(0.35-0.99)$ \\
\hline \multicolumn{7}{|c|}{ Setting of diabexs treatment } \\
\hline Primary care & $63(11.8 \%)$ & $1.02(0.58-1.81\}$ & $132(24.6 \%)$ & $1.38(0.82-2.33\}$ & $144(26.9 \%)$ & $1.26(0.76-209)$ \\
\hline \multicolumn{7}{|l|}{ Duration diaberss } \\
\hline 25 years & $53(13.4 \%)$ & $1.06(0.60-1.84)$ & $97(24.5 \%)$ & $0.96\langle 0.61-1.50\rangle$ & $85(21.5 \%)$ & $0.59(0.39-0.89)$ \\
\hline \multicolumn{7}{|c|}{ Opinion physical exercise } \\
\hline (much) Too little & $54(23.5 \%)$ & $5.03(2.88-8.79)$ & $59(2.5 .7 \%)$ & $1.37(0.86-2.18)$ & $51(22.2 \%)$ & $1.11(0.71-1.75)$ \\
\hline \multicolumn{7}{|l|}{ Eating disinhibition } \\
\hline Yes & $34(11.3 \%)$ & $1.34(0.77-2.32)$ & $112(37.2 \%)$ & $4.63(3.00-7.16)$ & $76(25.2 \%)$ & $1.66(1.09-252)$ \\
\hline
\end{tabular}

